\title{
Engagement with activity and functional status among older adults
}

\author{
Thomas Dombrowsky* \\ College of Nursing, The University of Texas at Arlington, USA
}

Do higher levels of activity protect against functional decline? If so, what types of activity are effective? There is good evidence for a protective relationship in the case of physical exercise [1,2]. Previous research has demonstrated that functional status is related to age [3], comorbidity [4], cognitive function [5], social support [6], and depression [7]. There is an association between cognitive exercises and slower mental decline among Alzheimer's patients [8]. Social engagement has also been found to be protective against functional decline [9].

Functional status is the ability to do daily self-care activities independently [10]. Functional status is a major component of quality of life for older adults and their families [11,12]. The total annual cost of care for functional decline in the United States is estimated to be 426 billion dollars [13]. Activity theory postulates that older adults generally wish to maintain activity related to their previous roles in society as long as possible, and that it is beneficial both for them both physically and mentally to maintain such activity [14].

Dombrowsky [15] found that engagement with activity is an independent predictor of functional status after controlling for age, comorbidity, and depression. Engagement is a construct that involves participation, commitment, and motivation for a specific activity [16]. It is unclear whether the more engaged participants were more engaged because they had better functional status or whether they had better functional status because they were more engaged. Longitudinal studies are needed to answer that question.

Functional status is often measured using the Katz Activities of Daily Living Index [17] and the Lawton-Brody Instrumental Activities of Daily Living Scale [18]. These two instruments are well suited for hospitalized patients, but suffer from a ceiling effect when used with community dwelling research participants [15]. They also fail to capture the contextual nature of functional status [19]. The practical meaning of functional status depends on the circumstances of one's life. It is one thing to manage one's money using a computer application and another thing to walk to the bank, withdraw money, and make rounds paying various bills. Whether or not one needs to manage money oneself depends on social context. The Katz and Lawton-Brody instruments do not capture this contextual characteristic of functional status and also fail to capture the distinction between functional capacity and functional performance. Functional capacity is what one could do if necessary. Functional performance is the level of functional activity one does in daily practice.

Just as existing measures of functional status are limited by ceiling effects and failure to capture all the dimensions of functional status, instruments for measuring engagement such as the Engagement with Meaningful Activities Survey [20] and the Meaningful Activities
Participation Assessment [21] suffer from similar limitations. A comprehensive measure of engagement would evaluate all dimensions of engagement based on theory, such as that of Lequerica and Korrte [16].

In response to the gaps mentioned in the preceding paragraphs, my current research focus is on the development of more sensitive and more comprehensive instruments for measuring functional status and engagement. My longer-term focus is on longitudinal studies of the relationship between engagement and functional status. Specifically, my research focus is on the question of whether increased levels of engagement with physical, social, cognitive, and productive activity correlate with better functional status at later time points.

\section{References}

1. Bonnefoy M, Boutitie F, Mercier C, Gueyffier F, Carre C, et al. (2012) Efficacy of a home-based intervention programme on the physical activity level and functional ability of older people using domestic services: A randomised study. J Nutr Health Aging 16: 370-377. [Crossref]

2. Dondzila CJ, Gennuso KP, Swartz AM, Tarima S, Lenz EK, et al. (2015) Doseresponse walking activity and physical function in older adults. J Aging Phys Act 23: 194-199. [Crossref]

3. Angleman SB, Santoni G, Von Strauss E, Fratiglioni L (2015) Temporal trends of functional dependence and survival among older adults from 1991 to 2010 in Sweden: Toward a healthier aging. J Gerontol A Biol Sci Med Sci 70: 746-752. [Crossref]

4. Huang H, Chang C, Liu L, Lin H, Chen C (2013) Trajectories and predictors of functional decline of hospitalised older patients. J Clin Nurs 22: 1322-1331. [Crossref]

5. Pennarts HM, Schouws SNTM, Bongers IMB (2014) Cognitive functioning in relation to self-care in elderly persons with a bipolar disorder. Clinical Gerontologist 37: 419428

6. McLaughlin D, Leung J, Pachana N, Flicker L, Hankey G, et al. (2012) Social support and subsequent disability: it is not the size of your network that counts. Age Ageing 41: 674-677. [Crossref]

7. Song H, Meade K, Akobundu U, Sahyoun N (2014) Depression as a correlate of functional status of community-dwelling older adults: Utilizing a short-version of 5-item Geriatric Depression Scale as a screening tool. J Nutr Health Aging 18: 765770. [Crossref]

8. Treiber KA, Carlson MC, Corcoran C, Norton MC, Breitner JC, et al. (2011) Cognitive stimulation and cognitive and functional decline in Alzheimer's disease: The Cache County Dementia Progression Study. J Gerontol B Psychol Sci Soc Sci 66: 416-425. [Crossref]

9. Chen L, Liu L, Liu C, Peng L, Lin M, et al. (2013) Predicting functional decline of older men living in veteran homes by Minimum Data Set: Implications for disability prevention programs in long term care settings. J Am Med Dir Assoc 14: 309 [Crossref]

*Correspondence to: Thomas Dombrowsky, College of Nursing, The University of Texas at Arlington, USA, Tel: 817-272-6881, E-mail: adthomas@uta.edu

Received: August 20, 2018; Accepted: August 25, 2018; Published: August 28, 2018 
10. Wang T (2004) Concept analysis of functional status. Int J Nurs Stud 41: 457-462. [Crossref]

11. Nichols LO, Martindale-Adams J, Greene WA, Burns R, Graney MJ, et al. (2009) Dementia caregivers' most pressing concerns. Clinical Gerontologist 32: 1-14.

12. Simone PM, Haas AL (2013) Frailty, leisure activity and functional status in older adults: Relationship with subjective wellbeing. Clinical Gerontologist 36: 275-293.

13. Congressional Budget Office (2013) Rising demand for long-term services and supports for elderly people.

14. Blace NP (2012) Functional ability, participation in activities and life satisfaction of the older people. Asian Social Science 8: 75-87.

15. Dombrowsky TA (2017) Relationship between engagement and level of functional status in older adults. SAGE Open Med 5: [Crossref]
16. Lequerica AH, Kortte K (2010) Therapeutic engagement: A proposed model of engagement in medical rehabilitation. Am J Phys Med Rehabil 89: 415-422. [Crossref]

17. Katz S, Akpom CA (1976) 12. Index of ADL. Medical Care 14: 116-118.

18. Lawton MP, Brody EM (1969) Assessment of older people: self-maintaining and instrumental activities of daily living. Gerontologist 9: 179-186. [Crossref]

19. Leidy NK (1994) Functional status and the forward progress of merry-go-rounds: Toward a coherent analytical framework. Nurs Res 43: 196-202. [Crossref]

20. Eakman AM (2011) Convergent validity of the engagement in meaningful activities survey in a college sample. OTJR 31: 23-32.

21. Eakman AM, Carlson ME, Clark FA (2010) The meaningful activity participation assessment: A measure of engagement in personally valued activities. Int J Aging Hum Dev 70: 299-317. [Crossref]

Copyright: ${ }^{0} 2018$ Dombrowsky T. This is an open-access article distributed under the terms of the Creative Commons Attribution License, which permits unrestricted use, distribution, and reproduction in any medium, provided the original author and source are credited. 